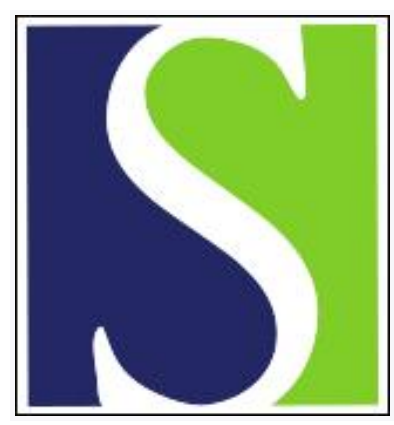

Scand J Work Environ Health 1996;22(2):146-149

https://doi.org/10.5271/sjweh.123

Issue date: Apr 1996

Diabetes mellitus among Swedish art glass workers -- an effect of arsenic exposure?

by Rahman M, Wingren $\mathrm{G}$, Axelson $\mathrm{O}$

Key terms: cancer; cardiovascular disease; case-control study; case-referent study; epidemiology; metal exposure; occupational arsenic exposure

This article in PubMed: www.ncbi.nlm.nih.gov/pubmed/8738894

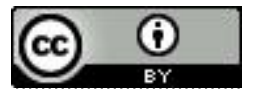




\title{
Diabetes mellitus among Swedish art glass workers - an effect of arsenic exposure?
}

by Mahfuzar Rahman, MD, ${ }^{1}$ Gun Wingren, PhD, ${ }^{1}$ Olav Axelson, MD ${ }^{1}$

\author{
Rahman M, Wingren G, Axelson 0 . Diabetes mellitus among Swedish art glass workers - an effect of arsenic \\ exposure? Scand $J$ Work Environ Health 1996;22:146-9.
}

\begin{abstract}
Objectives The purpose of this study was to search for evidence of an association between occupational arsenic exposure and diabetes mellitus, as implied by the relation of this disease to arsenic in drinking water in a recent study from Taiwan.

Methods A case-referent analysis on death records of 5498 individuals in the art glass producing part of southeastern Sweden was performed. Out of all the enrolled subjects, 888 were glass workers. According to occupational title, glassblowers, foundry workers, and unspecified workers were regarded as potentially exposed to arsenic. Persons with a diagnosis of diabetes mellitus either as an underlying or contributing cause of death were considered cases. Referents were decedents without any indication of cancer, cardiovascular disease, or diabetes.

Results A slightly elevated risk [Mantel-Haenszel odds ratio (MH-OR) 1.2, 95\% confidence interval (95\% CI) $0.82-1.8$ ] was found for diabetes mellitus among the glassworks employees, especially in combination with cardiovascular disease (MH-OR 1.4, 95\% CI 0.81-2.3). For the glassblowers, other foundry workers and unspecified glassworkers probably exposed to arsenic, the $\mathrm{M}-\mathrm{H}$ odds ratio was 1.4 (95\% CI $0.92-2.2$ ). Unspecified glass workers, who probably included persons with high exposure, carried the higher risk (MH-OR. $1.8,95 \%$ CI $1.1-2.8$ ).

Conclusions The observations from this study provide limited support for the possibility that occupational arsenic exposure could play a role in the development of diabetes mellitus. Many other metallic compounds are also used in art glass production, however, and there is a possibility of confounding.
\end{abstract}

Key terms cancer, cardiovascular disease, case-control, case-referent, epidemiologic, metal exposure, occupational.

Recently a study from Taiwan associated diabetes mellitus with exposure to arsenic in drinking water (1). Exposure to arsenic through drinking water is usually not a major health problem, except in some areas with abnormally high concentrations (2). There are many other situations that entail arsenic exposure, however, as summarized elsewhere (3). For example, a well-known occupational exposure to arsenic has occurred among copper smelter workers. Both worker groups and the general population can be exposed to organic and inorganic arsenic through the use of pesticides and wood preservatives. Another source of arsenic exposure has been the treatment of psoriasis with Fowler's solution.

In the glass industry, arsenic trioxide is used as a fining agent in the mixing of molten glass and in the removal of air bubbles during the melting process (4). Arsenic can also be used as a decoloring agent. Employ- ment in glassworks therefore means potential exposure to arsenic, but it also involves exposure to many other chemicals, especially metallic compounds, including lead, cadmium, nickel, chromium, copper, and selenium.

In view of the recent report (1) that diabetes mellitus may be related to arsenic exposure, we have analyzed existing case-referent data from the Swedish art glass industry to determine whether there was evidence to support this possible relationship.

\section{Subjects and methods}

The Swedish glass industry is located in a rather small area in the southeastern part of the country. The registers of deaths and burials in 11 parishes in this part of Sweden for the period 1950 - 1982 were used as the source of subjects for this study. All causes of death were coded according to the eighth revision of the International Clas-

1 Department of Occupational and Environmental Medicine University Hospital, Linköping, Sweden.

Reprint requests to: Professor Olav Axelson, Department of Occupational and Environmental Medicine, University Hospital, 58185 Linköping, Sweden. 
sification of Diseases (ICD 8) (5). In these parishes, 5498 men aged $\geq 45$ years had died, 888 of whom were identified as glassworks employees. The men with an indication of diabetes mellitus either as an underlying or contributing cause on the death certificates, as recast in the registers, were considered cases. Since, glass workers were previously shown to have an excess of cancer and cardiovascular disease (4), only the persons in the area who had died from nonmalignant, noncardiovascular, and nondiabetic diseases could be considered proper referents.

The assessment of potential arsenic exposure was based on the occupational title, which was specific for most subjects in the register of deaths and burials, and on our knowledge of the hygienic conditions in the glass industry. Since glass workers are skilled, there is considerable stability among this work force, and this tendency is enhanced by few opportunities to do other kinds of work in the area where the glass works are located. No specific exposure data were available from the past when, for example, batch mixing was not yet centralized, as it is today. From the registers, it was possible to distinguish the following six different occupational categories: (i) glassblowers, (ii) other foundry workers, (iii) grinders, engravers and similar workers, (iv) etchers, polishers, painters and similar workers, (v) controllers, packers and similar workers, and (vi) unspecified workers. Arsenic exposure was considered likely to have occurred especially among glassblowers, other foundry workers, and also among unspecified workers, but not to any pertinent extent among the other glass workers (ie, the third, fourth and fifth categories).

Those with occupational titles other than glass workers were considered to be unexposed and to represent the external population. They were mainly farmers, forestry workers, and men in service activities in the rather rural area where the glassworks are located.

In the analyses, crude odds ratios and Mantel-Haenszel odds ratios' (MH-OR) (6) were calculated along with the $95 \%$ confidence intervals $(95 \% \mathrm{CI})$. The subjects were stratified according to age into the categories 45 $64,65-74$ and $\geq 75$ years, respectively.

\section{Results}

When glassworks employment only was considered the exposure, there were 41 exposed and 199 unexposed cases versus 322 exposed and 1894 unexposed referents, the result being a moderately increased risk for diabetes mellitus (MH-OR 1.2, 95\% CI 0.82-1.8). The increased risk for diabetes mellitus mainly appeared in combination with cardiovascular disease (MH-OR 1.4, 95\% CI $0.81-2.3)$ and was not clearly elevated in the absence of such disease (MH-OR 1.1, 95\% CI 0.62-1.8).

When the glass workers were divided into different job categories, with glassblowers, foundry workers, and unspecified glass workers taken together as probably exposed to arsenic, the risk of diabetes mellitus was moderately increased when they were compared with those in the area who had not been employed in the glass industry (MH-OR 1.4, 95\% CI 0.90-2.1) (table 1). As also shown in the table, grinders, etchers, cutters, packers, controllers, and the like (third, fourth, and fifth categories), who probably had little or no exposure to arsenic, had no increased risk of diabetes mellitus.

In table 2, glassblowers, other foundry workers, and unspecified glass workers were considered exposed to arsenic, and the referents were the external population along with the categories of glass workers less likely to

Table 1. Cases (persons with diabetes mellitus) and referents (deceased from causes other than cardiovascular disease, cancer and diabetes mellitus) in the unexposed group and in the categories of glass workers probably exposed ${ }^{a}$ or unexposed ${ }^{b}$ to arsenic.

\begin{tabular}{lccc}
\hline $\begin{array}{l}\text { Age } \\
\text { group }\end{array}$ & $\begin{array}{c}\text { Unexposed } \\
(\mathrm{N})\end{array}$ & $\begin{array}{c}\text { Glassworkers } \\
\text { likely } \\
\text { unexposed } \\
(\mathrm{N})\end{array}$ & $\begin{array}{c}\text { Glassworkers } \\
\text { likely } \\
\text { exposed } \\
(\mathrm{N})\end{array}$ \\
\hline $\begin{array}{l}\text { 45-64 years } \\
\quad \text { Cases }\end{array}$ & 37 & 1 & 3 \\
$\quad$ Referents & 283 & 27 & 48 \\
$65-74$ years & & & \\
$\quad$ Cases & 51 & 3 & 9 \\
$\quad$ Referents & 416 & 33 & 53 \\
$\geq 75$ years & & & \\
$\quad$ Cases & 111 & 6 & 19 \\
Referents & 1195 & 53 & 108 \\
All ages & & & \\
$\quad$ Cases & 199 & 10 & 31 \\
Referents & 1894 & 113 & 209 \\
\hline $\begin{array}{l}\text { Crude odds ratio } \\
\text { Mantel Haenszel }\end{array}$ & $(1.0)$ & 0.8 & 1.4 \\
odds ratio & $(1.0)$ & 0.8 & 1.4 \\
$95 \%$ confidence interval & - & $0.39-1.6$ & $0.90-2.1$ \\
\hline
\end{tabular}

a Glassblowers, other foundry workers and unspecified workers.

- Grinders, engravers and similar workers, etchers, polishers painters and similar workers, controllers, packers and similar workers.

Table 2. Cases of diabetes mellitus and referents as in table 1 , with both glass workers without clear exposure to arsenic and all others in the study base (ie, not glass workers) being considered unexposed. Stratification as in table 1 not shown. $(O R=$ odds ratio, $\mathrm{MH}-\mathrm{OR}=$ Mantel Haenszel odds ratio, $95 \% \mathrm{Cl}=95 \%$ confidence interval)

\begin{tabular}{lrrrrc}
\hline $\begin{array}{l}\text { Exposure } \\
\text { categories }\end{array}$ & Referents Cases & $\mathrm{OR}$ & $\mathrm{MH}-\mathrm{OR}$ & $95 \% \mathrm{Cl}$ \\
\hline $\begin{array}{l}\text { All unexposed } \\
\text { (referents) }\end{array}$ & 2007 & 209 & $(1.0)$ & $(1.0)$ &. \\
$\begin{array}{l}\text { All exposed } \\
\text { categories }\end{array}$ & 209 & 31 & 1.4 & 1.4 & $0.92-2.2$ \\
$\begin{array}{l}\text { Glassblowers and } \\
\text { other foundry workers }\end{array}$ & 74 & 6 & 0.8 & 0.8 & $0.30-1.9$ \\
$\begin{array}{l}\text { Unspecified } \\
\text { glass workers }\end{array}$ & 135 & 25 & 1.8 & 1.8 & $1.1-2.8$ \\
\hline
\end{tabular}


have had contact with arsenic (ie, third, fourth, and fifth categories). In this comparison, the risk of diabetes mellitus was moderately increased for all the exposed persons (MH-OR 1.4, 95\% CI 0.92-2.2). The subgroup of unspecified glass workers proved to carry the risk when it was compared with the same reference (MH-OR 1.8, $95 \%$ CI $1.1-2.8$ ). When the combination of cardiovascular disease and diabetes mellitus was considered the case entity and the subset of unspecified glass workers was compared with the external population, the MantelHaenszel odds ratio rose to 2.1 with a $95 \%$ confidence interval of 1.2-3.7 (not shown in table).

\section{Discussion}

Mortality studies have been widely used to generate epidemiologic knowledge, despite the inherent limitations in the character of the data involved. Although based on limited numbers, moderately increased odds ratios, and relatively broad confidence intervals, the results of this study support the newly suggested hypothesis from Taiwan that exposure to arsenic might influence the development of diabetes mellitus (1). Diabetes mellitus is an important determinant of ischemic heart disease, and $51 \%$ of the exposed diabetics in this study died of cardiovascular disease as a primary cause of death. Another $7 \%$ of the exposed diabetic patients died of cancer as a primary cause of death. Among the unexposed diabetic patients, $42 \%$ died of cardiovascular disease and $8.5 \%$ died of cancer.

To some extent this mortality pattern resembles observations on populations with exposure to arsenic in drinking water in Chile, Mexico, and Taiwan, where a relation between inorganic arsenic and peripheral vascular disease and ischemic heart disease has been observed. An excess of cardiovascular disease has also been reported earlier for our glass worker population, as well as for other persons occupationally exposed to arsenic $(4,7,8)$. To some extent, this pattern also seems consistent with the suggestion by the Taiwanese investigators (1) that the elevated risk of cardiovascular disease in populations with arsenic exposure might have some background in an increased occurrence of diabetes mellitus.

The assessment of exposure in this study was less precise but still comparable to that in many other studies when based on job categories (eg, with the use of job exposure matrices). In view of the improved hygienic situation in the glass industry, there is no way to reconstruct historical dose estimates more precisely by hygienic surveys in today's glassworks. A dusty environment was present in the foundry in the past, especially in the mixing of the glass batch. In Sweden, this task has now been centralized to one special plant due to the hygienic problems involved in this procedure.

There are no historical exposure data available, but in the late 1980s a few air measurements in the Swedish glassworks revealed arsenic levels of less than $6 \mu \mathrm{g} \cdot \mathrm{m}^{-3}$ (10). In Norway arsenic levels between 3 and $48 \mu \mathrm{g} \cdot \mathrm{m}^{-3}$ have been measured in crystal glassworks (11), and from Italy levels of $5-619 \mu \mathrm{g} \cdot \mathrm{m}^{-3}$ have been reported for batch mixers and $0.6-3 \mu \mathrm{g} \cdot \mathrm{m}^{-3}$ for glassblowers and foundry workers (12). Prior to the introduction of centralized batch mixing, such levels are likely to have occurred in the Swedish glass industry as well.

The elevated risk of diabetes mellitus was found in the group of unspecified workers. It is likely that many glass workers with arsenic exposure, such as the batch mixers of the past, are included in this category, as they would not fit elsewhere. Furthermore, in a sample of our study population, we checked the occupational titles from the registers with information on the same persons given by the local representatives of the labor union and found that $59 \%$ of the unspecified glassworkers had worked in the foundry, $17 \%$ of them as glassblowers (13). These unspecified glassworkers also had elevated risks for cardiovascular disease and for cancer of the stomach, colon, and lung.

No information on smoking habits, dietary habits, or other life-style factors could be accounted for. Differences in these respects cannot be ruled out as playing some role in the results obtained, but confounding effects from such general factors are likely to be weak (14).

Finally there are also some experimental findings that can be considered supportive of a relationship between arsenic exposure and diabetes mellitus (13). Initial triphasic blood glucose response and transient secondary hyperglycemia were found in mice injected with hydroxylamine plus arsenite, and delayed hypoglycemia was observed in those treated with fluoroacetate or arsenite. From the same study, glucose-induced insulin secretion was significantly decreased in isolated pancreatic islets incubated with hydroxylamine plus arsenite (15).

The possible connection between long-term exposure to inorganic arsenic and diabetes mellitus has only recently attracted interest in view of the study from Taiwan (1). To our knowledge no other studies have been published as yet that convincingly support this possible relationship. We have reconsidered our data from a copper smelter (8), however, and found some support for an increased risk of diabetes in connection with arsenic exposure also in this population (16). It is suggested therefore that various sources of arsenic exposure might be considered for further studies to confirm or refute more definitely the indications obtained of a diabetogenic effect. Further toxicologic work seems to be needed as well.

\section{References}

1. Lai M-S, Hsueh Y-M, Chen C-J, Shyu M-P, Chen S-Y, Kuo T-L et al. Ingested inorganic arsenic and prevalence of diabetes mellitus. Am J Epidemiol 1994;139:485-91. 
2. World Health Organization (WHO). Environmental health criteria 18: Arsenic. Geneva: WHO, 1981.

3. International Agency for research on Cancer (IARC). Overall evaluations of carcinogenecity: an updating of IARC Monographs, volumes 1 to 42. Lyon: IARC, 1987. Monographs on the evaluation of carcinogenic risks to humans; suppl 7.

4. Wingren G. Epidemiological studies of health hazards related to Swedish art glass industry [dissertation]. Linköping (Sweden): Faculty of Health Sciences, 1991. Linköping University medical dissertations, no 346.

5. Socialstyrelsen. International statistical classification of diseases, injuries and causes of death, 1965 revision adapted for indexing of hospital records and morbidity statistics. Stockholm: Socialstyrelsen, 1973.

6. Mantel N, Haenszel W. Statistical aspects of the analysis of data from retrospective studies of disease. JNCI 1959;22: $719-48$.

7. Lee AM, Fraumeni JF. Arsenic and respiratory cancer in man: an occupational study. JNCI 1969;42:1045—52.

8. Axelson O, Dahlgren E, Jansson C-D, Rehnlund SO. Arsenic exposure and mortality: a case referent study from Swedish copper smelter. Br J Ind Med 1978;35:8-15.

9. Copper WC, Wong O, Kheifets L. Mortality among employees of lead battery plants and lead-producing plants, 19471980. Scand J Work Environ Health 1985;11:331-45.
10. Andersson L, Wingren G, Axelson O. Some hygienic observations from the glass industry. Int Arch Occup Environ Health $1990 ; 62 ; 249-52$.

11. Fyri M, Thomassen $Y$. Arsen og blyeksponering ved krystallglassproduksjon [Arsenic and lead exposure in the production of crystal glass]. Presented at the Nordic meeting on occupational hygiene, Åbo (Finland): 1981; 196.

12. Foá V, Colombi A Maroni M, Buratti M, Calzaferri G. The speciation of the chemical forms of arsenic in biological monitoring of exposure to inorganic arsenic. Sci Total Environ $1984 ; 34: 241-259$

13. Wingren $\mathrm{G}$, Axelson O. Mortality in the Swedish glassworks industry. Scand J Work Environ Health 1987;13:412-6.

14. Axelson $O$. Aspects of confounding in occupational health epidemiology [letter]. Scand J Work Environ Health 1978;4: $98-102$.

15. Boquist L, Boquist S, Ericsson I. Structural beta cell changes and transient hyperglycemia in mice treated with compounds inducing inhibited citric acid cycle enzyme activity. Diabetes 1988;37:89—98

16. Rahman M, Axelson O. Diabetes mellitus and arsenic exposure: a second look at case-control data from a Swedish copper smelter. Occup Environ Med. 1995;52:773-4.

Received for publication: 20 June 1995 